\title{
Resources for Teachers and Students at the Upper Midwest Environmental Sciences Center
}

\section{Center Foyer}

Educational experiences abound at the Upper Midwest Environmental Sciences Center (Center), 2630 Fanta Reed Road, La Crosse, Wisconsin. The main foyer is open to the public Monday through Friday, 8:00 a.m. to 4:00 p.m., and students and teachers can tour the Center during those times.

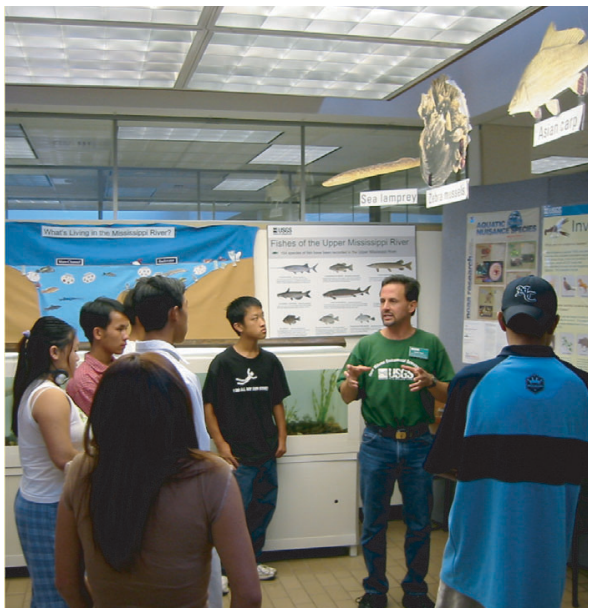

Educational displays and other learning activities are available for visitors:

- Invasive species (e.g., sea lampreys, round gobies, zebra mussels, Asian carp [silver and bighead])

- Migratory songbirds

- Native freshwater mussels

- Radiotelemetry methods used to track fish and wildlife for research

During a tour, students may also touch a lake sturgeon in a research laboratory and feed rainbow trout in the outdoor raceways.

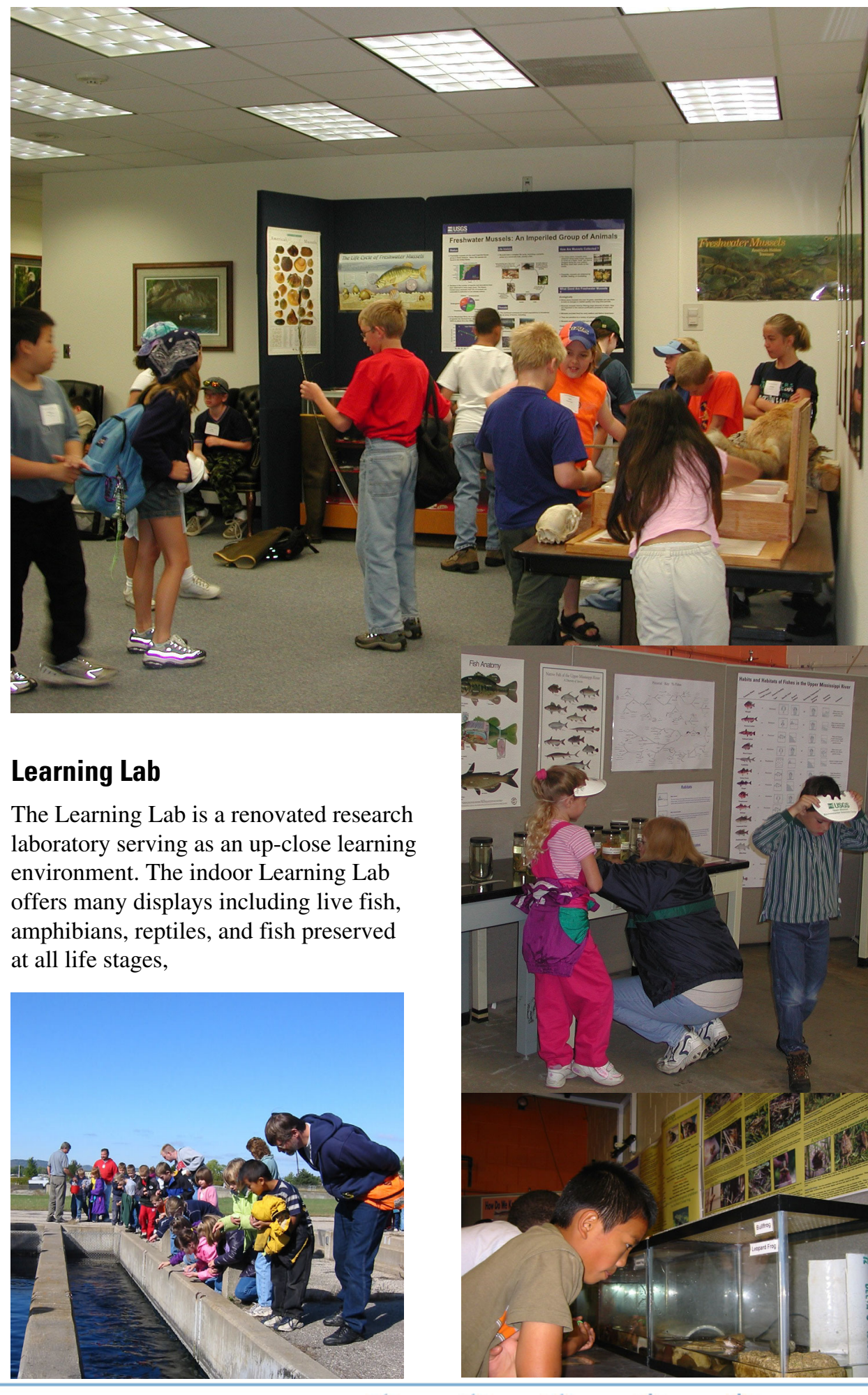

125 years of science for America
计
空
난 $\star$ 


\section{Outdoor Classroom}

The Outdoor Classroom is a handicapaccessible 600-ft. limestone screenings trail in the floodplain forest and over a backwater slough to an observation platform on Center grounds. Students from Longfellow Middle School's School-on-the-River program helped build the interactive educational displays mounted on the walkway of this learning site.

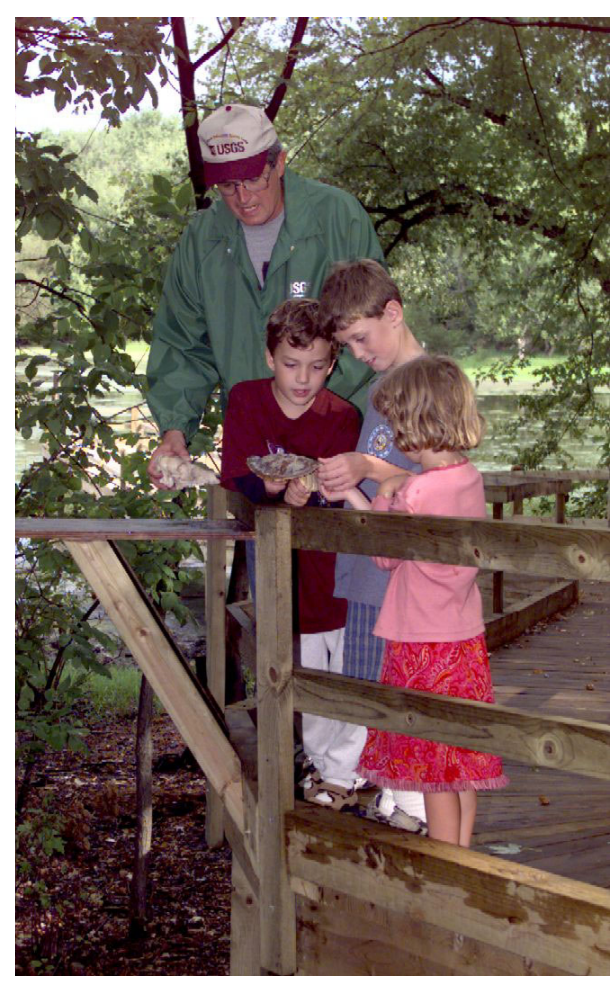

\section{Restored Native Prairie Tours}

Prairies historically covered large areas of the Upper Mississippi River floodplain. Agricultural development and fire suppession, however, have greatly reduced prairies in the Midwest. The Center was built on a relic sand priarie, and in 1997, approximately seven acres of Center grounds were restored and seeded as a natural prairie.
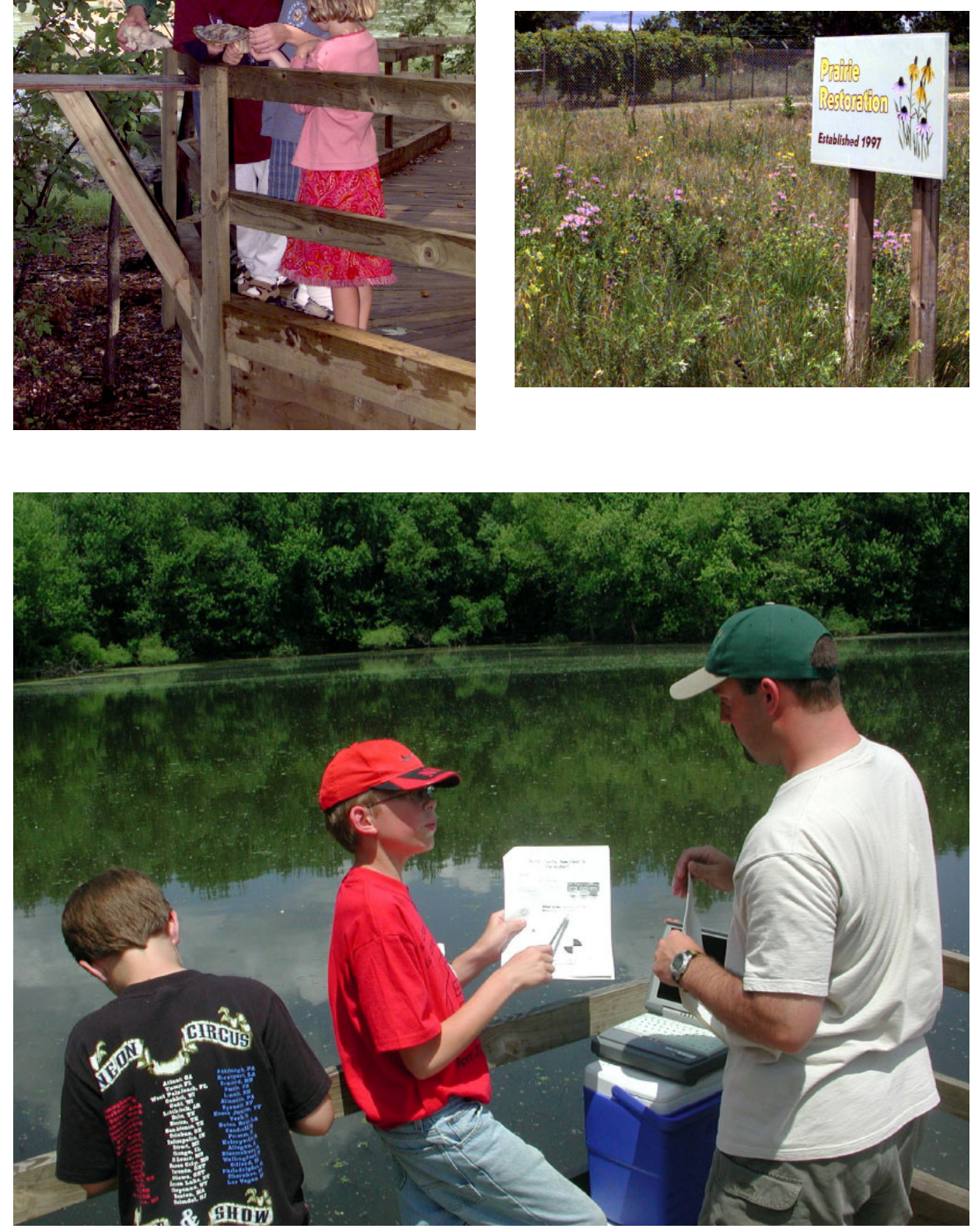

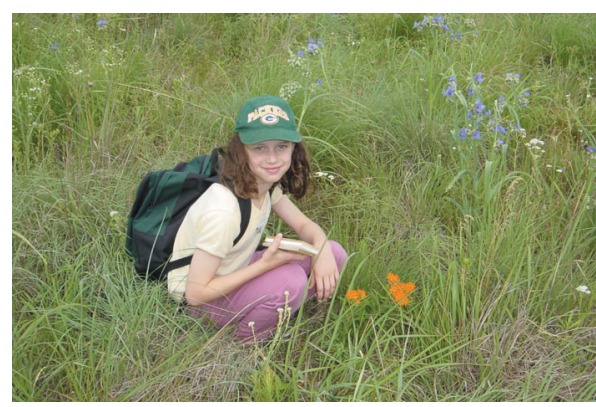

Schools can bring students on tours of the restored prairie, where a prairie naturalist will demonstrate the ecological value of prairie habitat and assist in the identification of prairie plants. Our prairie tours now feature an information kiosk and interpretive trail.

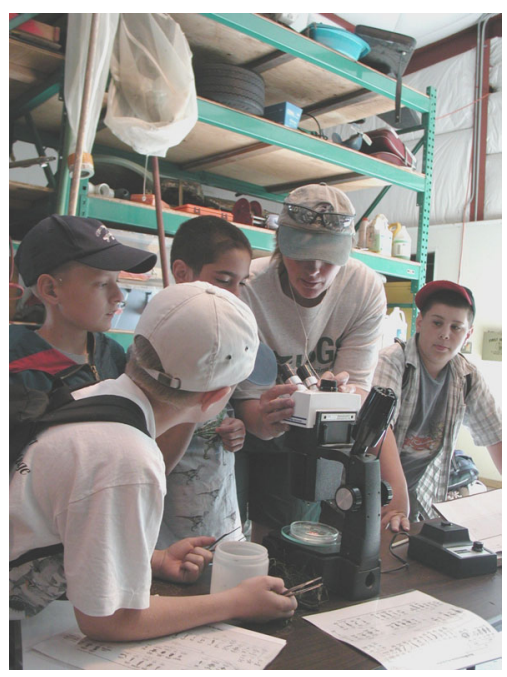

\section{Additional Resources}

Visit our Web site:

http://www.umesc.usgs.gov/ for more resources for teachers and students.

The Center Web site is a rich source on Center research programs, reports, and publications. The "Teachers and Students" section includes links to other Web sites about the Mississippi River and environmental education, a summary of educational opportunities at the Center, and interactive programs on radiotracked paddlefish and loons.

\section{For more information, contact-}

Randy Hines

USGS Upper Midwest Environmental

Sciences Center

2106 Fanta Reed Road

La Crosse, WI 54603

608.781.6398

rkhines@usgs.gov 